\title{
The Relationship Between Guideline-Recommended Initiation of Therapy, Outcomes, and Cost for Patients with Metastatic Non-Small Cell Lung Cancer
}

\author{
Adrianne Casebeer, PhD, MS, MPP; Dana Drzayich Antol, MS; Richard W. DeClue, MPH; \\ Sari Hopson, PhD, MSPH; Yong Li, PhD; Raya Khoury, MPH; Todd Michael, PharmD, RPh; \\ Marina Sehman, PharmD; Aparna Parikh, MD, MS; Stephen Stemkowski, PhD, MHA; \\ and Mikele Bunce, PhD
}

\begin{abstract}
BACKGROUND: Guideline-recommended therapy for metastatic non-small cell lung cancer (mNSCLC) encourages evidence-based treatment; however, there is a knowledge gap regarding the influence of guideline-recommended initiation of therapy on outcomes and cost.

OBJECTIVE: To investigate if lack of guideline-recommended initiation of first-line systemic therapy was associated with worse patient outcomes and increased costs for patients with mNSCLC.
\end{abstract}

METHODS: In this retrospective analysis, 1,344 Medicare patients with mNSCLC were identified from Humana data. Performance status (PS) was imputed using procedure, diagnosis, and durable medical equipment codes pre-index. Guideline-recommended initiation of therapy was defined as $\geq 1$ cycle of National Comprehensive Cancer Network-recommended first-line therapy based on age and PS or targeted therapies regardless of age and PS. Demographics and clinical characteristics were compared by guideline-recommended initiation of therapy. A Cox model assessed factors associated with 6-month mortality. End-of-life quality of care indicators included hospital admission and oncology infusions 30 days preceding death and were evaluated using logistic regression models. A generalized linear model assessed the relationship between guideline-recommended initiation of therapy and total health care costs in the 6 months post-index controlling for clinical, demographic, and treatment characteristics. Logistic models for inpatient stays and emergency department visits were also evaluated.

RESULTS: Guideline-recommended therapy initiation was observed in $75.5 \%$ of patients. Patients not initiating guideline-recommended therapy were older, with a mean (SD) age of 72.5 (6.7) versus 71.2 (6.2) years $(P=0.001)$, and more frequently identified as having a low-income subsidy $(30.0 \%$ vs. $16.4 \% ; P<0.001)$. Among the $24.6 \%$ of patients who died $\leq 6$ months post-index, a greater percentage had not initiated guideline-recommended therapy ( $28.8 \%$ vs. $23.2 \%$; $P=0.040$ ). In adjusted models, PS (not initiation of guideline-recommended therapy) was predictive of mortality (patients with poor PS had an $84 \%$ higher probability of death $[P=0.014]$ ). Among decedents, $64.2 \%$ were hospitalized, and $33.9 \%$ had an oncologyrelated infusion within 30 days of death, with no differences by guidelinerecommended initiation of therapy. These end-of-life quality indicators were not associated with guideline-recommended initiation of therapy in adjusted models. Overall, $47.5 \%$ of patients who initiated guideline-recommended therapy were hospitalized compared with $55.0 \%$ of patients who did not $(P=0.026)$. Patients initiating guideline-recommended therapy had higher post-index total and oncology-related health care costs and fewer hospitalizations. In models, these differences in costs and hospitalizations were not associated with initiation of guideline-recommended therapy.
CONCLUSIONS: Most patients initiated guideline-recommended therapy, with no differences in mortality and quality of care at the end of life by guideline-recommended initiation of therapy, though adherence beyond treatment initiation was not assessed. Unadjusted hospitalization rates were lower and costs were higher for patients who initiated guidelinerecommended therapy. These differences were no longer observed after risk adjustment, suggesting that they may have been influenced by patient characteristics, disease progression, and subsequent treatment decisions.

J Manag Care Spec Pharm. 2018;24(6):554-64

Copyright $\odot 2018$, Academy of Managed Care Pharmacy. All rights reserved.

\section{What is already known about this subject}

Patients with advanced lung cancer and poor performance status (PS) have an increased risk of mortality.

Treatment concordant with clinical guidelines improves the rates of morbidity and mortality for patients with non-small cell lung cancer (NSCLC).

The lack of readily available PS data in administrative claims limits the ability to assess guideline-recommended initiation of first-line systemic therapy for metastatic NSCLC in larger multisite national samples.

\section{What this study adds}

This study used a previously validated classification model to approximate Eastern Cooperative Oncology Group PS using claims data as a mechanism to assess treatment initiation according to national guideline recommendations in a large national sample of patients with Medicare coverage.

There were no differences in end-of-life care quality indicators by guideline-recommended initiation of first-line therapy, although adherence to therapy beyond initiation was not assessed.

Lower mortality rates and higher health care costs observed in unadjusted models were no longer present after risk adjustment, suggesting that these differences were influenced by factors other than initiation of guideline-recommended therapy, such as hospitalizations and patient and clinical factors. 
$\mathrm{L}$ ung cancer is the leading cause of cancer mortality for both men and women and is responsible for more than quarter of all deaths attributed to cancer each year in the United States. ${ }^{1,2}$ Annually, lung cancer is diagnosed in approximately 235,000 patients in the United States, ${ }^{3}$ with non-small cell lung cancer (NSCLC) accounting for approximately $80 \%-85 \%$ of all lung cancer cases. ${ }^{4}$ Lung cancer is most often diagnosed after metastasis. ${ }^{5}$ Patients with lung cancer are generally elderly; the mean age at diagnosis is about 70 years. For patients with metastatic lung cancer, the 5-year survival rate is $<5 \%$. In fact, more than half of patients with metastatic lung cancer die within a year of diagnosis.

The National Comprehensive Cancer Network (NCCN) has developed evidence-based guidelines for many cancer types including NSCLC. ${ }^{6-8}$ Guideline recommendations for first-line treatment for metastatic non-small cell lung cancer (mNSCLC) consider patient age, tumor history, and Eastern Cooperative Oncology Group (ECOG) performance status (PS). PS is a measure of a patient's functional capacity and has been found to predict survival in patients with cancer. ${ }^{9,10}$ NCCN guidelines balance the toxicity of a treatment with the age and ability of the patient to tolerate the treatment as indicated by PS. For patients with mNSCLC and good PS, the guidelines recommend chemotherapy. ${ }^{6}$ Palliative treatment is recommended in the elderly or for adults with poor PS.

Previous research has evaluated adherence to NCCN treatment guidelines for NSCLC and the association between guideline-adherent treatment and morbidity and mortality., ${ }^{6,11,12}$ These studies suggest that treatment adherent to clinical guidelines improved the rates of morbidity and mortality for patients with NSCLC; however, studies have also reported inconsistent adherence to various aspects of the clinical guidelines. For example, in a study considering concordance with NCCN guideline recommendations for initiation of first-line therapy for mNSCLC, Zornosa et al. (2012) found that $76 \%$ of patients received care consistent with NCCN guidelines. ${ }^{12}$ Another study by Wang et al. (2013) demonstrated that adherence rates to guidelines for adjuvant and first-line treatment of NSCLC were $61 \%$ and $75 \%$, respectively. ${ }^{11}$ Moreover, for patients with advanced NSCLC, adherence to guidelines for first-line treatment was correlated with a longer follow-up monitoring period. Salloum et al. (2012) reported similar results in patients $>50$ years old in that $71 \%$ received treatment based on current guidelines. ${ }^{13}$ The authors also suggested that the 29\% of patients who did not receive guideline-adherent therapy missed possible benefits of recommended therapy or received treatment associated with greater risk of harm than benefit.

In the assessment of guideline treatment adherence, these studies obtained PS from medical charts, were conducted in single institutions, and were limited to smaller sample sizes. As noted by Salloum et al. (2012), ${ }^{13}$ the lack of PS in medical claims has limited the ability to conduct larger, more generalizable studies of adherence to NSCLC treatment guidelines. Further, the physician assessment of PS utilized in these studies could have been subject to provider bias, where PS estimates may have been upgraded to justify treatment. To provide a less biased and more generalizable assessment of the effect of initiating first-line therapy according to guideline recommendations, our study adapted a classification model for imputing PS from claims data. ${ }^{14,15}$ The association between guideline-recommended initiation of first-line therapy and outcomes and cost was assessed; however, ongoing adherence to the guideline-recommended therapy was not evaluated. ${ }^{14,15}$ Specifically, this retrospective claims analysis investigated if lack of first-line systemic therapy initiation according to guideline recommendations was associated with worse patient outcomes and increased health care costs for patients with mNSCLC and Medicare coverage.

\section{Methods}

\section{Data Source}

Data were obtained from 2 sources for this retrospective cohort analysis: preservice consultation regarding biologic or chemotherapeutic infusions and administrative enrollment and medical and pharmacy claims data. The Humana Research Database was utilized for patients with Medicare Advantage Prescription Drug plan (MAPD) coverage. The database contained patient characteristics, diagnoses, and procedures, including chemotherapy administration. Preservice consultation data contained information that providers submitted as a request for consultation regarding biologic or chemotherapeutic infusions and included clinical factors pertinent to cancer diagnosis and treatment not available in claims data.

The research protocol was approved by an independent institutional review board (Schulman IRB).

\section{Sample Selection}

To be included in the study, patients with NSCLC enrolled in an MAPD must have been between 50 and 89 years of age at the first infusion, had a first-line NCCN-recommended drug regimen for NSCLC (oral or infused), and had documentation of at least 1 refill for drugs initiated on days 1-8 of first-line therapy. The refill requirement was intended to capture the regimen at initiation of therapy. The index date was the date of first treatment. Patients must also have been continuously enrolled 6 months pre- and post-index or until death. Patients participating in a clinical trial during the study period, as indicated in preservice consultation requests, were excluded.

Eligible patients were initially identified from oncology preservice consultation requests for NSCLC biologic or chemotherapy infusions during 2013 or 2014. Identification of patients with an NSCLC diagnosis using information submitted by clinicians from preservice consultation requests reduced cohort misclassification, as identification from claims data 
generally relies upon International Classification of Diseases, Ninth Revision, Clinical Modification (ICD-9-CM) diagnostic codes, and there is no specific ICD-9-CM code for NSCLC. However, there is a reliable ICD-9-CM code that can be used to ascertain metastatic status from claims data. Metastatic status was also available in preservice consultation data as reported by providers. As such, both preservice consultation data and claims were considered to determine if the NSCLC diagnosis was metastatic. Metastatic status in claims was identified as having at least 2 medical claims with ICD-9-CM codes for metastatic status (Appendix A, available in online article) occurring no more than 90 days apart with at least 1 occurring within 180 days before and up to 90 days after the index date.

\section{Study Measures}

Performance Status. In order to assess adherence to treatment guideline recommendations, ECOG PS was approximated using claims data. Davidoff et al. $(2013,2014)$ explored the use of disability status as a proxy for ECOG PS. ${ }^{14-16}$ They developed and validated a claims-based classification model predicting disability status using procedure, diagnosis, and durable medical equipment codes based on 12 months of claims data for a cohort of patients with Medicare. The imputed disability status was associated with mortality risk in this cohort. ${ }^{15}$ Among patients with NSCLC, disability status was a significant independent predictor of initiation of cancer-related treatment. ${ }^{14}$ In our study, at least 6 and up to 12 months of pre-index data were used to impute PS. The Davidoff disability model imputed poor PS (ECOG PS = 3-4) or good/moderate PS (ECOG PS = 0-2) based on the predicted likelihood of disability. In order to evaluate the initiation of guideline-recommended therapy, it was necessary to delineate moderate PS (ECOG PS $=2)$ from the disability model's assessment of good/moderate PS, which approximated ECOG PS of 0,1 , or 2 . We estimated moderate PS (ECOG PS =2) using the top quintile of the predicted likelihood of disability for patients with imputed good/moderate PS. A sensitivity analysis was conducted to determine if discrimination could be improved using either the top quartile or top sextile.

First-Line Treatment Regimen Categories. First-line NCCN guideline-recommended treatment categories included platinum doublet chemotherapy, single-agent chemotherapy, bevacizumab and chemotherapy, targeted agents, and other regimens. Treatment was identified in medical claims using procedure codes from the Healthcare Common Procedure Coding System (HCPCS; Appendix A). Any treatment initiated on days 1-8, with a second administration after day 8, was considered first-line therapy.

Guideline-Recommended Treatment Initiation. Guidelinerecommended initiation of therapy was defined as having claims evidence of at least 1 cycle of the applicable NCCN-recommended nontargeted first-line therapy based on age and imputed PS (Appendix B, available in online article). Patients with good PS were considered to have initiated guideline-recommended therapy if they initiated any NCCNrecommended first-line therapy, except single-agent therapy, which is not recommended for patients with good PS. Patients $<70$ years of age with moderate PS were considered to have initiated guideline-recommended therapy if they initiated a platinum doublet chemotherapy (before 2015), single-agent chemotherapy, new agent, and nonplatinum chemotherapy. Patients $\geq 70$ years of age with moderate PS were considered to have initiated guideline-recommended therapy if they initiated on single-agent, new agent, and nonplatinum chemotherapy. Consistent with applicable NCCN treatment guidelines, infusion therapy initiated by patients with poor PS was not considered guideline-recommended.

Targeted therapy requires tumor marker profiling, the results of which are not available in claims data. As a result, targeted therapies were considered guideline-recommended, regardless of age and PS. Though a treatment request for infusion therapy was required for study eligibility, oral and infused agents were also considered when assessing whether a patient's therapy was guideline-recommended.

Demographic and Clinical Characteristics. We used several patient characteristics as control variables in these analyses. Patient age at index, sex, race, and geographic region based on state of residence were determined from enrollment data. The low-income Part D subsidy for patients with Medicare provides assistance with Part D premiums, deductibles, and copayments and was used as a proxy for low-income status.

Comorbidity was measured using the Klabunde-enhanced Deyo-Charlson Comorbidity Index (CCI). ${ }^{17,18}$ The Deyo-CCI was calculated from claims in the 6 -month pre-index period. The prevalence of individual comorbid conditions considered in the comorbidity index calculation was also evaluated preindex and reported descriptively for those with a prevalence of at least 5\%. Pre-index radiation oncology therapy was identified from inpatient and outpatient medical claims using ICD-9-CM, Current Procedural Terminology (CPT), and revenue codes. The use of oxygen was identified in inpatient and outpatient medical claims using HCPCS codes (Appendix A).

Outcomes. Death (all-cause) within 6 months was identified based on the date of death provided to the health plan from the Centers for Medicare \& Medicaid Services. Quality of care at the end of life was measured as having biologic or chemotherapy infusions within 30 days of death or having an inpatient stay within 30 days of death. ${ }^{19}$

Utilization. Post-index health care utilization was compared for patients initiating guideline-recommended therapy to those who did not initiate guideline-recommended therapy. Health care resource utilization was evaluated as the percentage of patients having 1 or more all-cause hospitalization and 1 or 


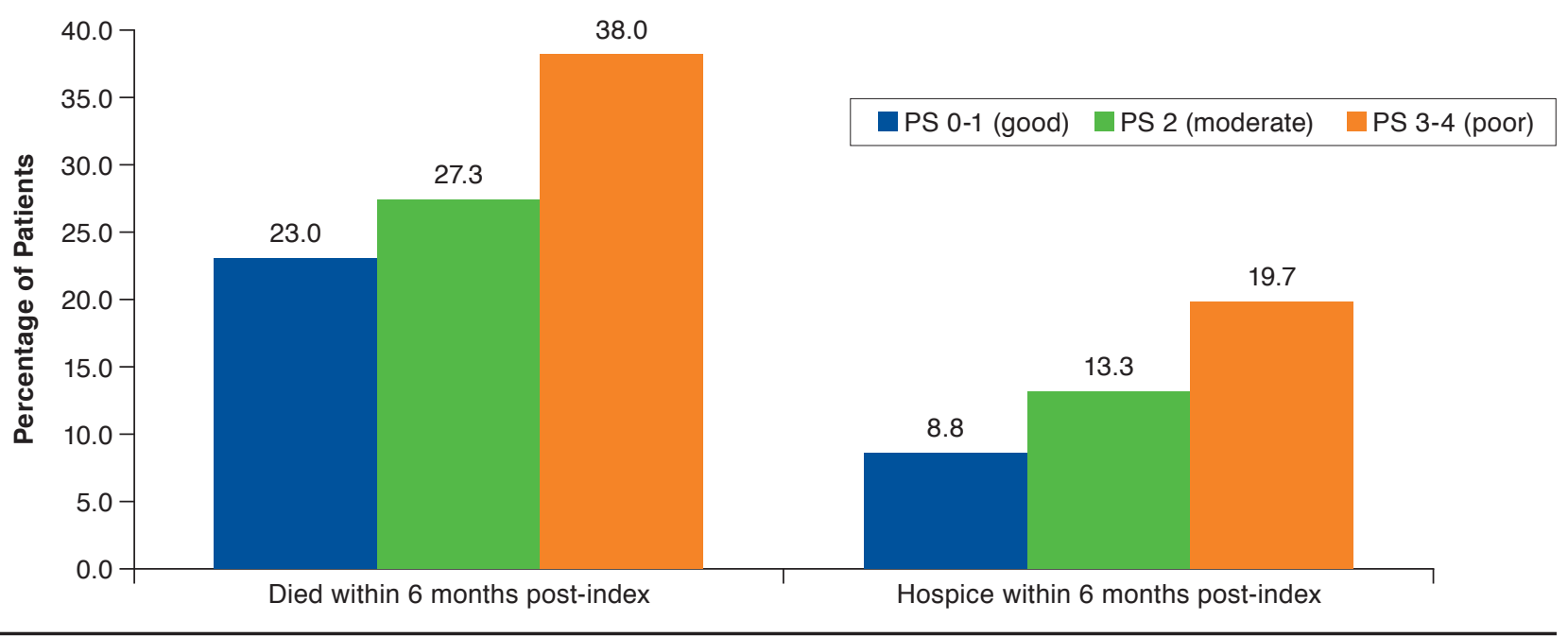

PS= performance status.

more all-cause emergency department visit in the 6-month post-index period.

Cost. All cost measures were health plan total allowed costs and included costs incurred by both the patient and the health plan. Total all-cause health care costs were defined as the sum of costs related to all medical and pharmacy claims occurring within 6 months post-index. Oncology-related costs included costs accrued at all places of service for oncology-related care including surgical procedures, infusions and infusion administration, radiation, diagnostics, imaging, and inpatient stays as identified by CPT and ICD-9-CM codes. Total oncology-related health care cost was the sum of all medical and pharmacy claims related to oncology treatment post-index. All health care costs were adjusted to 2015 U.S. dollars based on the medical care component of the Consumer Price Index.

\section{Statistical Analysis}

We compared the characteristics of patients who initiated firstline therapy according to guideline recommendations with those who did not using chi-square tests for categorical variables. T-tests and Wilcoxon tests were used for continuous variables.

In order to assess the effect of initiating guideline-recommend therapy on 6-month all-cause mortality, a multivariable Cox proportional hazards model was executed. The Cox model controlled for the following factors: age, sex, low-income Part D subsidy, Deyo-CCI, PS, pre-index use of radiation, and treatment initiation with platinum doublet chemotherapy. Results of the Cox model are reported as hazard ratios with a 95\% confidence interval.
To evaluate quality of care at the end of life for patients who died within 6 months post-index, 2 multivariable logistic regression models were used to assess the relationship between guideline-recommended initiation of first-line therapy having (a) an oncology-related infusion or (b) an inpatient stay in the last 30 days of life. These models were adjusted for the same variables used in the all-cause mortality model.

Two distinct multivariable logistic regression models were evaluated to determine if there was an increased odds of 1 or more post-index hospitalizations or emergency department visits by the initiation of guideline-recommended treatment. The models controlled for variables that may also affect hospitalization or emergency department visits, including pre-index utilization, age, sex, geographic region, low-income Part D subsidy, death during post-index, Deyo-CCI, imputed PS, and first-line treatment regimen category. In addition, the number of post-index months of observation was included to accommodate variations in follow-up time in the model, such as that of decedents.

The association between initiation of guideline-recommended therapy and total all-cause health care cost within 6 months post-index was evaluated using a generalized linear model (GLM). The model controlled for log of pre-index allcause health care costs and covariates included in the logistic regression model predicting utilization. Patients who initiated hospice during the post-index period were excluded from this model as hospice claims are incomplete in Medicare Advantage data. All statistical tests were 2-tailed and conducted in SAS Enterprise Guide, version 7.1 (SAS Institute, Cary, NC). Statistical significance was determined using a significance level of 0.05 established a priori. 
The Relationship Between Guideline-Recommended Initiation of Therapy, Outcomes, and Cost for Patients with Metastatic Non-Small Cell Lung Cancer

TABLE 1 Demographics and Clinical Characteristics by Initiation of Guideline-Recommended Therapy

\begin{tabular}{|c|c|c|c|c|}
\hline & $\begin{array}{c}\text { Overall } \\
\mathrm{N}=1,344\end{array}$ & $\begin{array}{c}\text { Guideline- } \\
\text { Recommended } \\
\text { Initiation } \\
\mathbf{n}=1,014\end{array}$ & $\begin{array}{c}\text { Nonguideline- } \\
\text { Recommended } \\
\text { Initiation } \\
\mathbf{n}=330\end{array}$ & $P$ Value $^{\mathrm{a}}$ \\
\hline \multicolumn{5}{|l|}{ Demographic characteristics } \\
\hline Age in years, mean (SD) & $(6.4)$ & $(6.2)$ & $(6.7)$ & 0.001 \\
\hline Female, n (\%) & $(45.8)$ & $(46.2)$ & $(44.5)$ & 0.611 \\
\hline \multicolumn{5}{|l|}{ Race, $\mathrm{n}(\%)$} \\
\hline White & $(85.1)$ & $(85.9)$ & $(82.7)$ & 0.160 \\
\hline Nonwhite & $(14.9)$ & $(14.1)$ & $(17.3)$ & \\
\hline \multicolumn{5}{|l|}{ Geographic region, $\mathbf{n}(\%)$} \\
\hline Northeast & $(1.2)$ & $(1.4)$ & $(0.6)$ & 0.619 \\
\hline Midwest & $(20.2)$ & $(20.5)$ & $(19.1)$ & \\
\hline South & $(75.1)$ & $(74.5)$ & $(77.0)$ & \\
\hline West & $(3.6)$ & $(3.6)$ & $(3.3)$ & \\
\hline Low-income Part D subsidy, n (\%) & $(19.7)$ & $(16.4)$ & $(30.0)$ & $<0.001$ \\
\hline \multicolumn{5}{|l|}{ Clinical characteristics, $\mathbf{n}(\%)$} \\
\hline Pre-index radiation & $(45.8)$ & $(47.1)$ & $(41.8)$ & 0.092 \\
\hline Pre-index home oxygen & $(17.9)$ & $(17.1)$ & $(20.6)$ & 0.145 \\
\hline Pre-index oncology surgery & $(8.0)$ & $(8.2)$ & $(7.6)$ & 0.723 \\
\hline Deyo-CCI, mean (SD) & $(3.3)$ & $(3.3)$ & $(3.4)$ & 0.518 \\
\hline \multicolumn{5}{|c|}{ Comorbid conditions (6-month pre-index) } \\
\hline Anemia & $(32.3)$ & $(30.7)$ & $(37.3)$ & 0.026 \\
\hline Anxiety & $(19.8)$ & $(18.1)$ & $(24.8)$ & 0.008 \\
\hline Autoimmune disorders & $(10.9)$ & $(9.8)$ & $(14.2)$ & 0.023 \\
\hline Ischemia & $(35.3)$ & $(35.3)$ & $(35.2)$ & 0.959 \\
\hline Cerebrovascular diseases & $(24.0)$ & $(22.8)$ & $(27.9)$ & 0.060 \\
\hline Depression & $(18.2)$ & $(17.1)$ & $(21.8)$ & 0.052 \\
\hline Hypertension & $(78.8)$ & $(79.2)$ & $(77.6)$ & 0.533 \\
\hline Renal disease, including ESRD & $(21.1)$ & $(19.0)$ & $(27.6)$ & 0.001 \\
\hline Diabetes mellitus & $(31.3)$ & $(30.6)$ & $(33.6)$ & 0.297 \\
\hline Pneumonia & $(26.2)$ & $(25.2)$ & $(29.1)$ & 0.168 \\
\hline Osteoporosis & $(8.6)$ & $(8.4)$ & $(9.1)$ & 0.690 \\
\hline \multicolumn{5}{|l|}{ Performance status } \\
\hline Good (PS = 0-1) & $(76.2)$ & $(88.6)$ & $(38.2)$ & $<0.001$ \\
\hline Moderate (PS = 2) & $(18.5)$ & $(11.1)$ & $(41.2)$ & \\
\hline Poor $(P S=3-4)$ & (5.3) & $(0.3)$ & $68 \quad(20.6)$ & \\
\hline
\end{tabular}

\section{Results}

For the 1,344 patients with mNSCLC, imputed PS was assigned as good for $76.2 \%$ of patients, moderate for $18.5 \%$ of patients, and poor for $5.3 \%$ of patients. To assess the discrimination of the imputed PS classification, the proportion of patients who died or initiated hospice in the 6 months post-index was compared by imputed PS level (Figure 1). The frequency of death or hospice initiation significantly increased with worsening levels of imputed PS classification $(P=0.009$ and $P=0.003$, respectively).

Guideline-recommended first-line therapy was initiated by $75.5 \%$ of patients with mNSCLC (Appendix B). The mean age of the cohort was 71.5 years $( \pm 6.4 ; 10.5 \%$ of the cohort were aged $<65$ ), $45.8 \%$ were female, and $85.1 \%$ were white (Table 1 ). Patients with nonguideline-recommended initiation of therapy were older and more frequently had a low-income Part D subsidy. There was no difference in Deyo-CCI score by guideline-recommended initiation of therapy; however, more frequent anemia, anxiety, autoimmune disorders, and renal disease were found in patients who initiated treatment with nonguideline-recommended therapies.

Better PS was observed among patients with guidelinerecommended initial therapies (Table 1). Among patients with guideline-recommended initial therapies, PS was imputed as good for $88.6 \%$ of patients; for patients with 


\begin{tabular}{|c|c|c|c|c|}
\hline & Overall & \begin{tabular}{|c|} 
Guideline- \\
Recommended \\
Initiation of \\
Therapy \\
\end{tabular} & \begin{tabular}{|c|} 
Nonguideline- \\
Recommended \\
Initiation of \\
Therapy
\end{tabular} & $P$ Value $^{\mathrm{a}}$ \\
\hline Mortality & $\mathrm{N}=1,344$ & $\mathrm{n}=1,014$ & $\mathbf{n}=330$ & \\
\hline Died within 6 months of index, $\mathrm{n}(\%)$ & $330(24.6)$ & $235(23.2)$ & $95(28.8)$ & 0.040 \\
\hline End-of-life quality measures among patients who died within 6 months of index & $\mathrm{n}=330$ & $\mathrm{n}=235$ & $\mathrm{n}=95$ & \\
\hline Hospital admission 30 days before death, $\mathrm{n}(\%)$ & $212(64.2)$ & $148 \quad(63.0)$ & $64 \quad(67.4)$ & 0.451 \\
\hline Oncology-related infusion 30 days before death, $\mathrm{n}(\%)$ & $112(33.9)$ & $79(33.6)$ & $33(34.7)$ & 0.846 \\
\hline Unadjusted utilization & $\mathrm{n}=1,207$ & $\mathrm{n}=918$ & $\mathrm{n}=289$ & \\
\hline$\geq 1$ inpatient stay, $\mathrm{n}(\%)$ & $595 \quad(49.3)$ & $436 \quad(47.5)$ & $159(55.0)$ & 0.026 \\
\hline$\geq 1$ emergency department visit, $\mathrm{n}(\%)$ & $667 \quad(55.3)$ & $494 \quad(53.8)$ & $173(59.9)$ & 0.071 \\
\hline Unadjusted costs & $\mathrm{n}=1,207$ & $\mathrm{n}=918$ & $\mathrm{n}=289$ & \\
\hline \multicolumn{5}{|l|}{ Total health care costs, $\$$} \\
\hline Median (IQR) & $41,304(37,266)$ & $42,294(38,989)$ & $38,006(33,566)$ & 0.021 \\
\hline Mean (SD) & $47,535(32,067)$ & $48,703(32,624)$ & $43,827(29,984)$ & 0.024 \\
\hline \multicolumn{5}{|l|}{ Total oncology-related costs, \$ } \\
\hline Median (IQR) & $34,427(34,015)$ & $35,679(35,025)$ & $31,054(28,272)$ & 0.003 \\
\hline Mean (SD) & $41,621(30,697)$ & $43,001 \quad(31,227)$ & $37,236(28,385)$ & 0.004 \\
\hline \multicolumn{5}{|l|}{ Outpatient costs, $\$$} \\
\hline Median (IQR) & $6,336(19,505)$ & $6,637 \quad(19,631)$ & $5,178(18,903)$ & 0.432 \\
\hline Mean (SD) & $15,523(23,594)$ & $15,812(24,265)$ & $14,605(21,336)$ & 0.418 \\
\hline \multicolumn{5}{|l|}{ Pharmacy costs, \$ } \\
\hline Median (IQR) & $1,079 \quad(2,056)$ & $1,081 \quad(2,003)$ & $1,069 \quad(2,122)$ & 0.804 \\
\hline Mean (SD) & $4,028 \quad(9,822)$ & $4,359 \quad(10,515)$ & $2,978 \quad(7,102)$ & 0.011 \\
\hline
\end{tabular}

aT-tests were used to compare continuous variables. Categorical variables were compared using chi-square analysis.

$I Q R=$ interquartile range; $S D=$ standard deviation

nonguideline-recommended initiation of therapy, PS was ascribed as good for $38.2 \%$ of patients $(P<0.001)$.

Nearly 25\% ( $\mathrm{n}=330)$ of patients died within 6 months postindex (Table 2). In unadjusted analysis, a greater proportion of patients who did not initiate guideline-recommended therapy died within 6 months of initiating treatment (28.8\% vs. 23.2\%; $P=0.040)$. In an adjusted Cox model, there was no difference in 6-month all-cause mortality between patients who initiated guideline-recommended therapy and those who did not (Table 3). However, poor PS increased the hazard of death by $83.5 \%$ while being female decreased the hazard of death by $37.0 \%$.

Hospitalizations and oncology-related infusions in the 30 days before death were evaluated as end-of-life quality indicators. Among the 330 patients who died within 6 months post-index, $64.2 \%$ of patients were hospitalized and 33.9\% had an oncology-related infusion within 30 days of death (Table 2). There was no significant difference in the proportion of patients admitted to the hospital in the last 30 days of life between those who initiated treatment according to guideline recommendations and those who did not $(63.0 \%$ vs. $67.4 \%$, respectively; $P=0.451$ ). There also was no difference in having oncology-related infusions in the last 30 days of life by guideline-recommended initiation of therapy. In multivariable logistic regression models, the odds of having an inpatient stay or having an oncology-related infusion in the last 30 days of life were not influenced by whether or not the initiation of first-line therapy aligned with guideline recommendations (Table 3).

Patients who initiated care according to guideline recommendations had fewer inpatient stays than patients who did not $(47.5 \%$ vs. $55.0 \%$; $P=0.026$; Table 2$)$. A smaller proportion of patients with 1 or more emergency department visits was observed for those who initiated treatment according to guideline recommendations $(53.8 \%$ vs. $59.9 \% ; P=0.071)$. In multivariable regression models, these utilization differences were not attributable to the initiation of treatment but to higher post-index mortality and pre-index utilization among patients who did not initiate treatment according to guideline recommendations (Table 4).

In unadjusted analyses, post-index total all-cause health care costs and total oncology-related health care costs were higher for patients who initiated guideline-recommended therapy compared with those who did not (Table 2). Specifically, median (interquartile range [IQR]) total all-cause health care costs were $\$ 42,294(\$ 38,989)$ for patients who initiated guideline-recommended therapy compared with $\$ 38,006(\$ 33,566)$ for those who did not $(P=0.021)$. Total oncology-related costs 
TABLE 3 Models Assessing Factors Associated with 6-Month All-Cause Mortality and Predicting Hospital Admissions or Oncology-Related Infusions 30 Days Before Death

\begin{tabular}{|c|c|c|c|c|c|c|}
\hline & \multicolumn{2}{|c|}{ 6-Month All-Cause Mortality ${ }^{a}$} & \multicolumn{2}{|c|}{$\begin{array}{l}\text { Hospital Admission } 30 \text { Days } \\
\text { Before Death }^{\text {b }}\end{array}$} & \multicolumn{2}{|c|}{$\begin{array}{l}\text { Oncology-Related Infusion } \\
30 \text { Days Before Death }\end{array}$} \\
\hline & HR $(95 \% \mathrm{CI})$ & $P$ Value & OR $(95 \% \mathrm{CI})$ & $P$ Value & OR $(95 \% \mathrm{CI})$ & $P$ Value \\
\hline NCCN guideline-recommended initiation of therapy & $0.987(0.723-1.347)$ & 0.935 & $0.598(0.294-1.216)$ & 0.156 & $0.799(0.400-1.595)$ & 0.524 \\
\hline Age & $0.998 \quad(0.981-1.015)$ & 0.832 & $0.937(0.901-0.975)$ & 0.001 & $0.960(0.924-0.997)$ & 0.035 \\
\hline Female vs. male & $0.630(0.503-0.790)$ & $<0.001$ & $1.153 \quad(0.702-1.893)$ & 0.573 & $0.604(0.362-1.007)$ & 0.053 \\
\hline Low-income Part D subsidy & $1.098(0.830-1.453)$ & 0.513 & $0.566 \quad(0.311-1.028)$ & 0.062 & $0.881 \quad(0.475-1.633)$ & 0.687 \\
\hline Deyo-CCI & $1.021 \quad(0.988-1.055)$ & 0.223 & $0.973(0.904-1.048)$ & 0.469 & $1.070(0.993-1.154)$ & 0.075 \\
\hline PS: $3-4$ vs. $0-1$ & $1.835(1.132-2.972)$ & 0.014 & $0.610 \quad(0.209-1.781)$ & 0.366 & $0.749(0.253-2.220)$ & 0.603 \\
\hline PS: 2 vs. $0-1$ & $1.190(0.870-1.628)$ & 0.276 & $1.562 \quad(0.797-3.063)$ & 0.194 & $0.763 \quad(0.398-1.461)$ & 0.414 \\
\hline Pre-index radiation therapy & $1.007(0.806-1.257)$ & 0.952 & $1.141 \quad(0.707-1.839)$ & 0.589 & $1.289(0.798-2.084)$ & 0.300 \\
\hline Regimen: doublet chemotherapy & $0.841(0.644-1.099)$ & 0.205 & $1.237(0.672-2.277)$ & 0.495 & $0.935 \quad(0.507-1.723)$ & 0.829 \\
\hline
\end{tabular}

were $\$ 35,679(\$ 35,025)$ for patients who initiated guidelinerecommended treatment compared with $\$ 31,054(\$ 28,272)$ for patients who did not initiate guideline-recommended therapy $(P=0.003)$. There were no differences in outpatient or pharmacy costs in unadjusted analyses. An adjusted GLM assessing factors associated with post-index total all-cause health care costs found no association between initiating treatment according to guideline recommendations and total all-cause health care costs (Table 4). Differences in costs were attributable to patient and treatment characteristics.

\section{Discussion}

This study investigated the association between the initiation of guideline-recommended treatment and patient outcomes (including mortality, hospice, and end-of-life quality indicators) and health care utilization and costs for patients with mNSCLC. In adjusted analyses, no differences in outcomes or costs based on the initiation of guideline-recommended first-line systemic therapy for mNSCLC were found. However, in unadjusted analyses, there was an increased rate of inpatient stays for patients who did not initiate therapy according to guidelines. While increased mortality and costs for patients whose treatment initiation was not in alignment with guideline recommendations were found in unadjusted analyses, these differences were no longer present in adjusted multivariable models. This suggests that factors associated with the determination of the initiation of guideline-recommended therapy-and not the therapy itselfinfluenced patient outcomes and health care costs.

Using real-world data from a national cohort, we focused on the initiation of first-line systemic treatment rather than the trajectory of the entire course of treatment. In a study of patients with mNSCLC treated at NCCN institutions,
Zornosa et al. (2012) found that $75.5 \%$ of patients had treatment congruent with NCCN guideline recommendations. ${ }^{12}$ Despite the differences in study design, the current study found that $75.4 \%$ of patients initiated first-line systemic treatment in alignment with NCCN guideline recommendations.

Additionally, Zornosa et al. evaluated the reasons for mNSCLC treatment discordant with guideline recommendations. Their study showed that among patients with good or moderate PS, the most commonly observed reasons for treatment misalignment with NCCN recommendations were that it was not recommended by the provider or the patient died before treatment began. For the remainder of patients, the most common reason that treatment diverged from guideline recommendations was that patients were treated with erlotinib or pemetrexed before these treatments were added as first-line treatment options in the guidelines. ${ }^{12}$ The current study took place after erlotinib and pemetrexed were added to the guidelines. In this study, systemic treatment that was not initiated according to NCCN guideline recommendations was most commonly found among patients with poor PS. For these patients, the guideline recommendation was a palliative approach to treatment ${ }^{6}$; however, maintenance measures were observed. Providers may partially base these treatment decisions on findings such as Feliciano et al. (2015), who found that patients with mNSCLC and poor PS derived a survival benefit from chemotherapy but not to the same extent as patients with good PS. ${ }^{16}$

The current study found no association between the initiation of guideline-recommended therapy and mortality in multivariable models for patients with mNSCLC, though adherence to guideline-recommended initial therapy was not assessed. Treatment guidelines are intended to promote evidence-based practice in order to optimize patient outcomes, including 
TABLE 4 Adjusted Utilization and Costs by Initiation of Guideline-Recommended Therapy Among Patients Who Did Not Initiate Hospice Within 6 Months of Index

\begin{tabular}{|c|c|c|c|c|}
\hline Adjusted Utilization ${ }^{a}$ & OR & $95 \%$ CI & $P$ Value & \\
\hline \multicolumn{4}{|l|}{ Inpatient stays } & \\
\hline$\geq 1$ pre-index inpatient stay & 1.602 & $1.240-2.070$ & $<0.001$ & \\
\hline Died during follow-up & 6.490 & $3.356-12.551$ & $<0.001$ & \\
\hline \multicolumn{4}{|l|}{ Emergency department visits } & \\
\hline$\geq 1$ pre-index emergency department visit & 1.918 & $1.494-2.462$ & $<0.001$ & \\
\hline Died during follow-up & 5.068 & $2.550-10.074$ & $<0.001$ & \\
\hline Adjusted Costs ${ }^{b}$ & $\begin{array}{l}\text { Guideline-Recommended } \\
\text { Initiation of Therapy }\end{array}$ & $\begin{array}{c}\text { Nonguideline- } \\
\text { Recommended Initiation } \\
\text { of Therapy }\end{array}$ & $P$ Value & \\
\hline \multicolumn{4}{|l|}{ Total predicted health care costs } & \\
\hline \multirow[t]{2}{*}{ Mean $(95 \%$ CI), \$ } & $60,133(52,417-68,984)$ & $55,135(48,433-62,764)$ & 0.131 & \\
\hline & Estimate & SE & $95 \%$ CI & $P$ Value \\
\hline Pre-index log of total health care costs & 0.129 & 0.027 & $0.075-0.182$ & $<0.001$ \\
\hline Age & -0.007 & 0.003 & $-0.013--0.001$ & 0.017 \\
\hline Region: West vs. South & 0.185 & 0.093 & $0.004-0.367$ & 0.046 \\
\hline Regimen: bevacizumab vs. platinum doublet therapy & 0.815 & 0.068 & $0.683-0.948$ & $<0.001$ \\
\hline Regimen: other vs. platinum doublet therapy & 0.341 & 0.116 & $0.113-0.568$ & 0.003 \\
\hline Died during follow-up & 0.332 & 0.080 & $0.176-0.488$ & $<0.001$ \\
\hline Months of follow-up & 0.183 & 0.025 & $0.134-0.233$ & $<0.001$ \\
\hline \multicolumn{5}{|c|}{$\begin{array}{l}\text { aTwo distinct multivariable logistic regression models were used for adjusted utilization measures. Only statistically significant results are presented. Other variables } \\
\text { adjusted for in the models included guideline-recommended initiation of therapy, age, sex, region, low-income Part D subsidy, Deyo-CCI, imputed PS, first-line treatment } \\
\text { regimen (platinum doublet therapy vs. others), and months of follow-up post-index. } \\
\text { bA generalized linear model was used to predict total health care costs post-index. Adjusted mean costs by guideline-recommended initiation of therapy and statistically } \\
\text { significant variables are presented. Other variables adjusted for in the model included guideline-recommended initiation of therapy, sex, region (Midwest and Northeast vs. } \\
\text { South), Deyo-CCI, imputed PS, and first-line treatment regimen (single-agent vs. platinum doublet therapy). } \\
\text { CI= confidence interval; CCI=Charlson Comorbidity Index; OR=odds ratio; PS= performance status; SE=standard error. }\end{array}$} \\
\hline
\end{tabular}

reducing the risk of mortality. The association between clinical guideline concordance and improved mortality rates has been established previously. ${ }^{20}$ The lack of association between initiation of guideline-recommended therapy and mortality in our study may suggest that improvements in mortality rates are found when the continuity of treatment, beyond initiation of first-line treatment, is congruent with NCCN guideline recommendations. As with previous research, our study found that mortality rates were increased for patients with poor PS compared with those with good PS at the initiation of treatment. ${ }^{10}$

Claims-based indicators to assess the quality of care at the end of life for patients with cancer have been proposed by Earle et al. (2010). ${ }^{19}$ Among those indicators were (a) continuation of ongoing treatments near death, (b) inpatient hospital stays near death, and (c) percentage of patients never initiating hospice. Similar quality of care measures at the end of life were evaluated in the current study by initiation of NCCN guideline-recommended first-line treatment. In adjusted analysis, no association was found between initiating therapy according to guideline recommendations and an inpatient stay or oncology-related infusion in the last 30 days of life. Additionally, hospice initiation rates did not differ by initiation of guideline-recommended treatment. Active treatment of patients with poor PS has been shown to improve survival, although there are concerns about the effect of treatment tolerability and toxicity on health-related quality of life.

Neubauer et al. (2010) found that the initiation of guidelinerecommended therapy for MNSCLC was associated with lower outpatient costs. ${ }^{21}$ This study was able to extend the evaluation of the association between the initiation of guidelinerecommended therapy and health care cost beyond outpatient costs to total all-cause health care costs. Unadjusted postindex costs were higher for patients with initial therapy by guideline recommendation for mNSCLC patients; however, these differences were explained by patient and treatment characteristics in adjusted multivariable analyses. Differences in all-cause total health care cost between patients with guideline-recommended and nonguideline-recommended treatment initiation may be attributable to patient-level characteristics and prescribed treatment regimens. These findings may suggest that factors influencing initiation of guideline-recommended therapy — and not the initiation of therapy itself - may lead to cost differentials within this population. 


\section{Limitations}

This study has limitations that need to be considered. Patients with NSCLC were identified for this study using physician requests for preservice consultation regarding the initiation of first-line biologic or chemotherapeutic infusion therapy. Patients with NSCLC not referred for infusion therapy, including those on oral treatment only, were not included in this study, potentially affecting the generalization of the study findings. This study considered guideline-recommended therapy at initiation of treatment and did not assess adherence beyond initiation of therapy.

PS was imputed from a validated classification model ${ }^{14,15}$; however, the modification to distinguish moderate PS from the imputed good/moderate PS has not been validated. The Davidoff disability model has been validated with mortality and initiation of cancer treatment but not directly compared with ECOG PS, although the measure may more broadly capture markers of decreased functional status as it considers use of durable medical equipment and other indicators of the sequelae of disability. We found differences in PS by guidelinerecommended initiation of therapy; this may be due to unexplained clinical differences between the cohorts.

Further limitations include that the latest immunotherapies and targeted therapies for genotype mutations were introduced after the study time period, precluding them from inclusion in this study. These therapies may be appropriate for mNSCLC patients and need to be considered in future research efforts. In addition, utilization and cost data after a patient initiates hospice may be incomplete as they are not all administered by Medicare Advantage. Finally, there was no adjustment applied for costs at the end of life for patients who died during the postindex period to account for the expected rise in health care costs at the end of life.

\section{Conclusions}

Most patients initiated guideline-recommended therapy, with no differences in mortality and quality of care at the end of life by guideline-recommended initiation of therapy, although adherence beyond treatment initiation was not assessed. Unadjusted hospitalization rates were lower and costs were higher for patients who initiated guideline-recommended therapy. These differences were no longer observed after controlling for patient characteristics, suggesting that they may have been influenced by patient characteristics, disease progression, and subsequent treatment decisions. The findings of this study may suggest that patient outcomes are more closely associated with patient characteristics and the totality of treatment beyond the initiation of first-line therapy in accordance with guideline recommendations.

\section{Authors}

ADRIANNE CASEBEER, PhD, MS, MPP; DANA DRZAYICH ANTOL, MS; RICHARD W. DECLUE, MPH; SARI HOPSON, PhD, MSPH; YONG LI, PhD; and STEPHEN STEMKOWSKI, PhD, MHA, Comprehensive Health Insights, Humana, Louisville, Kentucky. RAYA KHOURY, MPH; TODD MICHAEL, PharmD, RPh; APARNA PARIKH, MD, MS; and MIKELE BUNCE, PhD, Genentech, South San Francisco, California. MARINA SEHMAN, PharmD, Humana, Louisville, Kentucky.

AUTHOR CORRESPONDENCE: Adrianne Casebeer, PhD, MS, MPP, 515 W. Market St., Louisville, KY 40202. Tel.: 703.789.7643; E-mail: acasebeer@humana.com.

\section{DISCLOSURES}

This study was sponsored by Genentech. Khoury, Michael, Parikh, and Bunce are employed by Genentech. Casebeer, Drzayich Antol, DeClue, Hopson, Li, and Stemkowski are employed by Comprehensive Health Insights, Humana, which was contracted by Genentech to conduct this study. Sehman is employed by Humana.

Based on this research, 2 posters were presented at the Academy of Managed Care Pharmacy Nexus 2017 on October 16-19, 2017, in Dallas, Texas. Another poster was also presented at the International Society for Pharmacoeconomics and Outcomes Research (ISPOR) Annual European Congress on October 29-November 2, 2016, in Vienna, Austria.

\section{ACKNOWLEDGMENTS}

The authors acknowledge Amy Davidoff, PhD, Yale School of Public Health, for her feedback on earlier drafts of this manuscript and for sharing the SAS code for the disability status algorithm. The authors also acknowledge Bryan Loy, MD, for his review and comments on this manuscript and Mary Costantino, PhD, and Neelam David, PharmD, for medical writing support.

\section{REFERENCES}

1. American Lung Association. Lung cancer fact sheet. Available at: http:// www.lung.org/lung-disease/lung-cancer/resources/facts-figures/lung-cancerfact-sheet.html. Accessed April 25, 2018.

2. American Cancer Society. Cancer facts \& figures 2016. Available at: https://www.cancer.org/research/cancer-facts-statistics/all-cancer-factsfigures/cancer-facts-figures-2016.html. Accessed April 16, 2018.

3. American Cancer Society. Key statistics for lung cancer. Revised February 8, 2018. Available at: https://www.cancer.org/cancer/non-small-cell-lungcancer/about/key-statistics.html. Accessed April 25, 2018.

4. American Cancer Society. What is non-small cell lung cancer? Revised May 16, 2016. Available at: http://www.cancer.org/cancer/lungcancer-nonsmallcell/detailedguide/non-small-cell-lung-cancer-what-is-non-small-celllung-cancer. Accessed April 25, 2018.

5. Noone AM, Howlader N, Krapcho M, et al., eds. SEER cancer statistics review, 1975-2015. Based on November 2017 SEER data submission, posted to the SEER web site April 2018. National Cancer Institute. Bethesda, MD. Available at: https://seer.cancer.gov/csr/1975_2015/. Accessed April 25, 2018.

6. Ettinger DS, Wood DE, Akerley W, et al. NCCN guidelines insights: non-small cell lung cancer, Version 4.2016. J Natl Compr Canc Netw. 2016;14(3):255-64.

7. García-Campelo R, Bernabé R, Cobo M, et al. SEOM clinical guidelines for the treatment of non-small cell lung cancer (NSCLC) 2015. Clin Transl Oncol. 2015;17(12):1020-29. 
8. Eberhardt WE, De Ruysscher D, Weder W, et al. 2nd ESMO consensus conference in lung cancer: locally advanced stage III non-small-cell lung cancer. Ann Oncol. 2015;26(8):1573-88.

9. Oken MM, Creech RH, Tormey DC, et al. Toxicity and response criteria of the Eastern Cooperative Oncology Group. Am J Clin Oncol. 1982;5(6):649-55.

10. Albain KS, Crowley JJ, LeBlanc M, Livingston RB. Survival determinants in extensive-stage non-small-cell lung cancer: the Southwest Oncology Group experience. J Clin Oncol. 1991;9(9):1618-26.

11. Wang Z, Askamit I, Tuscher L, Bergstrom K. Rates of guideline adherence among US community oncologists treating NSCLC. Am J Manag Care. 2013;19(3):185-92.

12. Zornosa C, Vandergrift JL, Kalemkerian GP, et al. First-line systemic therapy practice patterns and concordance with NCCN guidelines for patients diagnosed with metastatic NSCLC treated at NCCN institutions. J Natl Compr Canc Netw. 2012;10(7):847-56

13. Salloum RG, Smith TJ, Jensen GA, Lafata JE. Factors associated with adherence to chemotherapy guidelines in patients with non-small cell lung cancer. Lung Cancer. 2012;75(2):255-60.

14. Davidoff AJ, Gardner LD, Zuckerman IH, Hendrick F, Ke X, Edelman MJ. Validation of disability status, a claims-based measure of functional status for cancer treatment and outcomes studies. Med Care. 2014;52(6):500-10.
15. Davidoff AJ, Zuckerman IH, Pandya N, et al. A novel approach to improve health status measurement in observational claims-based studies of cancer treatment and outcomes. J Geriatr Oncol. 2013;4(2):157-65.

16. Feliciano J, Gardner L, Hendrick F, Edelman MJ, Davidoff A. Assessing functional status and the survival benefit of chemotherapy for advanced non-small cell lung cancer using administrative claims data. Lung Cancer. 2015;87(1):59-64

17. Deyo RA, Cherkin DC, Ciol MA. Adapting a clinical comorbidity index for use with ICD-9-CM administrative databases. J Clin Epidemiol. 1992;45(6):613-19.

18. Klabunde CN, Potosky AL, Legler JM, Warren JL. Development of a comorbidity index using physician claims data. J Clin Epidemiol. 2000;53(12):1258-67.

19. Earle CC, Park ER, Lai B, Weeks JC, Ayanian JZ, Block S. Identifying potential indicators of the quality of end-of-life cancer care from administrative data. J Clin Oncol. 2003;21(6):1133-38.

20. Nadpara PA, Madhavan SS, Tworek C, Sambamoorthi U, Hendryx M, Almubarak M. Guideline-concordant lung cancer care and associated health outcomes among elderly patients in the United States. J Geriatr Oncol. 2015;6(2):101-10.

21. Neubauer MA, Hoverman JR, Kolodziej M, et al. Cost effectiveness of evidence-based treatment guidelines for the treatment of non-small-cell lung cancer in the community setting. J Oncol Pract. 2010;6(1):12-18. 
The Relationship Between Guideline-Recommended Initiation of Therapy, Outcomes,

and Cost for Patients with Metastatic Non-Small Cell Lung Cancer

\begin{tabular}{|c|c|}
\hline \multicolumn{2}{|c|}{ APPENDIX A Study Codes } \\
\hline Code Type & Codes \\
\hline $\begin{array}{l}\text { ICD-9-CM codes } \\
\text { (for metastatic cancer) }\end{array}$ & 196.xx, 197.xx, 198.xx, 199.0, 199.1 \\
\hline $\begin{array}{l}\text { HCPCS Level II codes } \\
\text { (for cancer treatment) }\end{array}$ & $\begin{array}{l}\text { J9035, C9257, J9045, J9055, J9060, J9062, } \\
\text { J9171, J9170, J8560, J9181, J9201, J9208, } \\
\text { J9206, J9280, J9265, J9264, J9267, J9305, } \\
\text { J9360, J9375, J9380, J9390, J8999, J9290, } \\
\text { J9291 }\end{array}$ \\
\hline $\begin{array}{l}\text { HCPCS codes } \\
\text { (for radiation) }\end{array}$ & $\begin{array}{l}\text { 77261-77499, 77600-77620, 77750-77799, } \\
\text { 79200-79999, 77261-77499, 77600-77620, } \\
77750-77799,79200-79999\end{array}$ \\
\hline $\begin{array}{l}\text { Revenue codes } \\
\text { (for radiation therapy) }\end{array}$ & $0330,0333,0339,0342$ \\
\hline $\begin{array}{l}\text { ICD-9-CM procedure } \\
\text { and diagnostic codes } \\
\text { (for radiation therapy) }\end{array}$ & $\begin{array}{l}92.21,92.22,92.23,92.24,92.25,92.26 \\
92.27,92.28,92.29,99.85, \text { V } 58.0\end{array}$ \\
\hline $\begin{array}{l}\text { HCPCS codes } \\
\text { (for home oxygen use) }\end{array}$ & $\begin{array}{l}\text { C1300, E0424, E0430, E0431, E0433, E0434, } \\
\text { E0435, E0439, E0440, E0441, E0442, E0443, } \\
\text { E0444, E1354, E1356, E1357, E1358, E1390, } \\
\text { E139, E1392, E1405, E1406, K0738, S8120, } \\
\text { S8121 }\end{array}$ \\
\hline $\begin{array}{l}C P C S=\text { Healthcare } C o \\
D-9-C M=\text { Internation } \\
\text { linical Modification. }\end{array}$ & $\begin{array}{l}\text { rocedure Coding System; } \\
\text { ification of Diseases, Ninth Revision, }\end{array}$ \\
\hline
\end{tabular}

\begin{tabular}{|c|c|c|c|c|}
\hline \multirow[t]{2}{*}{ APP } & \multicolumn{4}{|c|}{$\begin{array}{l}\text { NDIX B Distribution of Guideline- } \\
\text { Recommended and Nonguideline- } \\
\text { Recommended Initial Therapies }\end{array}$} \\
\hline & \multicolumn{2}{|c|}{$\begin{array}{l}\text { Guideline-Recommended } \\
\text { Initiation of Therapy } \\
\quad \mathrm{n}=1,014\end{array}$} & \multicolumn{2}{|c|}{$\begin{array}{l}\text { Nonguideline-Recommended } \\
\text { Initiation of Therapy } \\
\mathbf{n}=330\end{array}$} \\
\hline PS/Age & First-Line Therapy & n (\%) & First-Line Therapy & n (\%) \\
\hline \multirow[t]{5}{*}{$\begin{array}{l}\text { PS } 0-1 \\
\text { (all ages) }\end{array}$} & $\begin{array}{l}\text { Platinum doublet } \\
\text { chemotherapy }\end{array}$ & $\begin{array}{c}797 \\
(78.6)\end{array}$ & $\begin{array}{l}\text { Single-agent } \\
\text { chemotherapy }\end{array}$ & $\begin{array}{c}123 \\
(37.3)\end{array}$ \\
\hline & $\begin{array}{l}\text { Bevacizumab and } \\
\text { chemotherapy }\end{array}$ & $\begin{array}{c}82 \\
(8.1)\end{array}$ & $\begin{array}{l}\text { Cetuximab, } \\
\text { vinorelbine, and } \\
\text { cisplatin (2015) }\end{array}$ & $\begin{array}{c}0 \\
(0.0)\end{array}$ \\
\hline & $\begin{array}{l}\text { New agent and } \\
\text { nonplatinum } \\
\text { chemotherapy }\end{array}$ & $\begin{array}{c}0 \\
(0.0)\end{array}$ & \multirow[t]{3}{*}{ Other regimen } & \multirow[t]{3}{*}{$\begin{array}{c}3 \\
(0.9)\end{array}$} \\
\hline & $\begin{array}{l}\text { Cetuximab, } \\
\text { vinorelbine, and } \\
\text { cisplatin ( } 2013 \text { and } \\
2014 \text { only) }\end{array}$ & $\begin{array}{c}1 \\
(0.1)\end{array}$ & & \\
\hline & Targeted agent & $\begin{array}{l}18 \\
(1.8)\end{array}$ & & \\
\hline \multirow[t]{4}{*}{$\begin{array}{l}\text { PS } 2 \\
(<70 \\
\text { years })\end{array}$} & $\begin{array}{l}\text { Platinum doublet } \\
\text { chemotherapy ( } 2013 \\
\text { and } 2014 \text { only) } \\
\end{array}$ & $\begin{array}{c}66 \\
(6.5)\end{array}$ & $\begin{array}{l}\text { Platinum doublet } \\
\text { chemotherapy (2015) }\end{array}$ & $\begin{array}{c}9 \\
(2.7)\end{array}$ \\
\hline & $\begin{array}{l}\text { Single-agent } \\
\text { chemotherapy }\end{array}$ & $\begin{array}{c}19 \\
(1.9)\end{array}$ & $\begin{array}{l}\text { Bevacizumab and } \\
\text { chemotherapy }\end{array}$ & $\begin{array}{c}6 \\
(1.8) \\
\end{array}$ \\
\hline & $\begin{array}{l}\text { New agent and } \\
\text { nonplatinum } \\
\text { chemotherapy }\end{array}$ & $\begin{array}{c}0 \\
(0.0)\end{array}$ & $\begin{array}{l}\text { Cetuximab, } \\
\text { vinorelbine, and } \\
\text { cisplatin }\end{array}$ & $\begin{array}{c}0 \\
(0.0)\end{array}$ \\
\hline & Targeted agent & $\begin{array}{c}0 \\
(0.0) \\
\end{array}$ & Other regimen & $\begin{array}{c}0 \\
(0.0) \\
\end{array}$ \\
\hline \multirow{4}{*}{$\begin{array}{l}\text { PS } 2 \\
(\geq 70 \\
\text { years })\end{array}$} & $\begin{array}{l}\text { Single-agent } \\
\text { chemotherapy }\end{array}$ & $\begin{array}{c}24 \\
(2.4)\end{array}$ & $\begin{array}{l}\text { Platinum doublet } \\
\text { chemotherapy }\end{array}$ & $\begin{array}{c}114 \\
(34.5)\end{array}$ \\
\hline & $\begin{array}{l}\text { New agent and } \\
\text { nonplatinum } \\
\text { chemotherapy }\end{array}$ & $\begin{array}{c}1 \\
(0.1)\end{array}$ & $\begin{array}{l}\text { Bevacizumab and } \\
\text { chemotherapy }\end{array}$ & $\begin{array}{c}7 \\
(2.1)\end{array}$ \\
\hline & \multirow[t]{2}{*}{ Targeted agent } & \multirow[t]{2}{*}{$\begin{array}{c}3 \\
(0.3)\end{array}$} & $\begin{array}{l}\text { Cetuximab, } \\
\text { vinorelbine, and } \\
\text { cisplatin }\end{array}$ & $\begin{array}{c}0 \\
(0.0)\end{array}$ \\
\hline & & & Other regimen & $\begin{array}{c}0 \\
(0.0)\end{array}$ \\
\hline \multirow[t]{6}{*}{$\begin{array}{l}\text { PS 3-4 } \\
\text { (all ages) }\end{array}$} & \multirow[t]{6}{*}{ Targeted agent } & \multirow[t]{6}{*}{$\begin{array}{c}3 \\
(0.3)\end{array}$} & $\begin{array}{l}\text { Platinum doublet } \\
\text { chemotherapy }\end{array}$ & $\begin{array}{c}52 \\
(15.8) \\
\end{array}$ \\
\hline & & & $\begin{array}{l}\text { Bevacizumab and } \\
\text { chemotherapy }\end{array}$ & $\begin{array}{c}4 \\
(1.2)\end{array}$ \\
\hline & & & $\begin{array}{l}\text { Single-agent } \\
\text { chemotherapy }\end{array}$ & $\begin{array}{c}12 \\
(3.6)\end{array}$ \\
\hline & & & $\begin{array}{l}\text { New agent and } \\
\text { non-platinum } \\
\text { chemotherapy }\end{array}$ & $\begin{array}{c}0 \\
(0.0)\end{array}$ \\
\hline & & & $\begin{array}{l}\text { Cetuximab, } \\
\text { vinorelbine, and } \\
\text { cisplatin }\end{array}$ & $\begin{array}{c}0 \\
(0.0)\end{array}$ \\
\hline & & & Other regimen & $\begin{array}{c}0 \\
(0.0)\end{array}$ \\
\hline
\end{tabular}

